\title{
VIEWPOINT
}

\section{Stress hyperglycemia: an essential survival response!}

\author{
Paul E Marik,** and Rinaldo Bellomo²
}

\begin{abstract}
Stress hyperglycemia is common in critically ill patients and appears to be a marker of disease severity. Furthermore, both the admission as well as the mean glucose level during the hospital stay is strongly associated with patient outcomes. Clinicians, researchers and policy makers have assumed this association to be causal with the widespread adoption of protocols and programs for tight in-hospital glycemic control. However, a critical appraisal of the literature has demonstrated that attempts at tight glycemic control in both ICU and non-ICU patients do not improve health care outcomes. We suggest that hyperglycemia and insulin resistance in the setting of acute illness is an evolutionarily preserved adaptive responsive that increases the host's chances of survival. Furthermore, attempts to interfere with this exceedingly complex multi-system adaptive response may be harmful. This paper reviews the pathophysiology of stress hyperglycemia and insulin resistance and the protective role of stress hyperglycemia during acute illness.
\end{abstract}

In 1878, Claude Bernard described hyperglycemia during hemorrhagic shock [1]; and it is now well known that acute illness or injury may result in hyperglycemia, insulin resistance and glucose intolerance, collectively termed stress hyperglycemia. Numerous studies in both ICU and hospitalized non-ICU patients have demonstrated a strong association between stress hyperglycemia and poor clinical outcomes, including mortality, morbidity, length of stay, infections and overall complications [2-5]. This association is well documented for both the admission as well as the mean glucose level during the hospital stay. Based on these data clinicians, researchers and policy makers have assumed this association to be

*Correspondence: marikpe@evms.edu

'Division of Pulmonary and Critical Care Medicine, Eastern Virginia Medical School, Norfolk, VA, USA

Full list of author information is available at the end of the article causal with the widespread adoption of protocols and programs for tight or intensive in-hospital glycemic control. However, a critical appraisal of the data has consistently demonstrated that attempts at intensive glycemic control in both ICU and non-ICU patients do not improve health care outcomes [6-8]. Indeed, NICESUGAR, a large randomized, multi-center trial performed in 6,104 ICU patients, demonstrated that intensive glucose control ( 81 to $108 \mathrm{mg} / \mathrm{dl}$ ) increased mortality when compared to conventional glucose control [9]. Although NICE-SUGAR targeted a blood glucose between 144 and $180 \mathrm{mg} / \mathrm{dL}$, there is no evidence that targeting an even more tolerant level between 180 and $220 \mathrm{mg} / \mathrm{dL}$ would not, in fact, have been better (or worse). This information suggests that the degree of hyperglycemia is related to the severity of the disease and is an important prognostic marker. This is, however, not a cause and effect relationship. Indeed, Green and colleagues [10] demonstrated that hyperglycemia was not predictive of mortality in non-diabetic adults with sepsis after correcting for blood lactate levels, another marker of physiological stress. Tiruvoipati and colleagues [11] demonstrated that those patients with septic shock who had stress hyperglycemia had a significantly lower mortality than those with normal blood glucose levels. We suggest that hyperglycemia in the setting of acute illness is an evolutionarily preserved adaptive response that increases the host's chances of survival. Furthermore, iatrogenic attempts to interfere with this exceedingly complex multi-system adaptive response may be harmful. Only patients with severe hyperglycemia (blood glucose $>220 \mathrm{mg} / \mathrm{dl}$ ) may benefit from moderate glycemic control measures; however, this postulate is untested.

\section{Acute illness, the stress response and stress hyperglycemia}

The stress response is mediated largely by the hypothalamic-pituitary-adrenal (HPA) axis and the sympathoadrenal system. In general, there is a graded response to the degree of stress. Cortisol and catecholamine levels correlate with the type of surgery, the severity of injury, the Glasgow Coma Scale and the APACHE score [12]. Adrenal cortisol output increases up to ten-fold with severe stress (approximately $300 \mathrm{mg}$ hydrocortisone per day) [12]. In patients with shock, plasma concentrations 


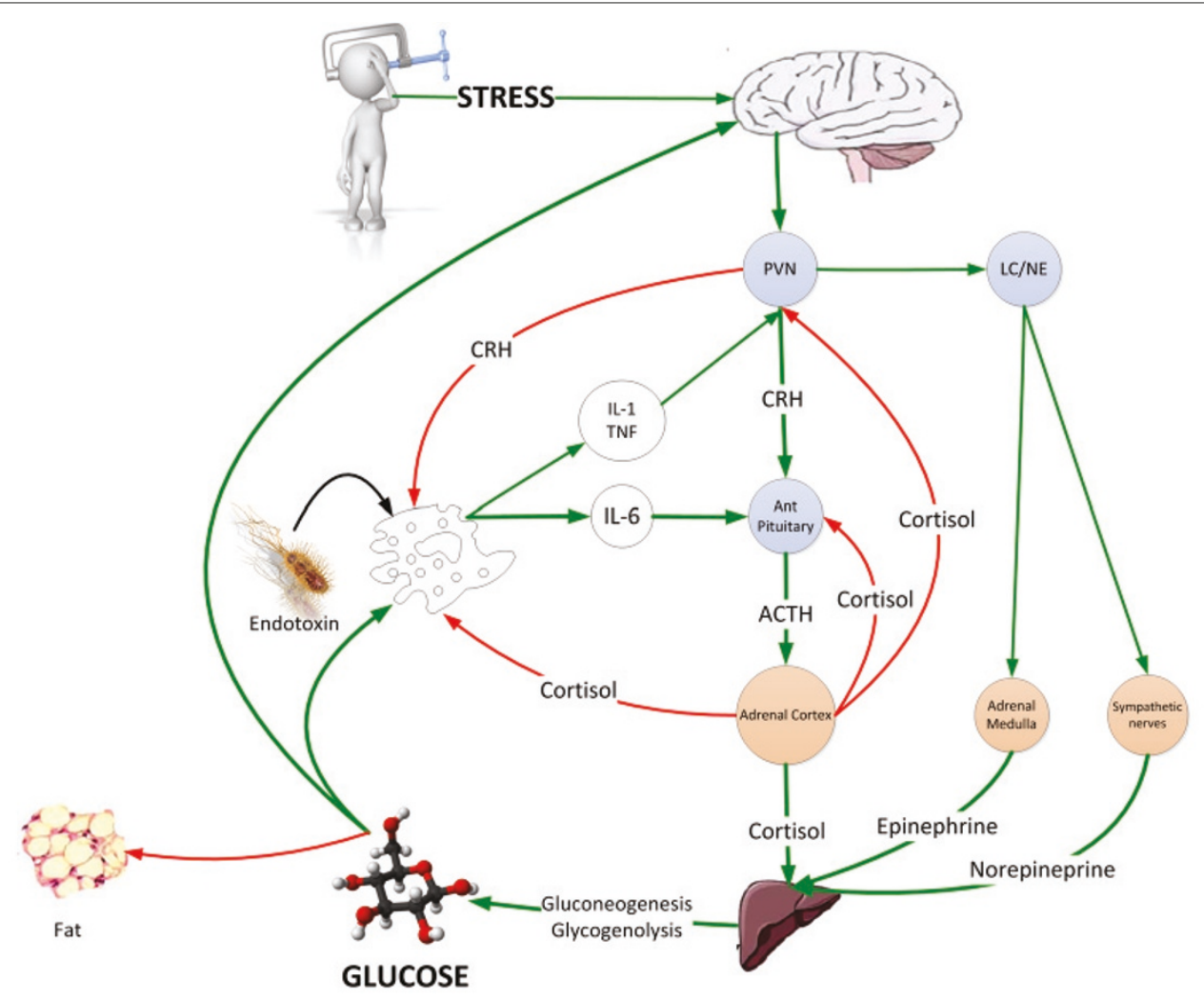

Figure 1. The neuroendocrine response to stress is characterized by gluconeogenesis and glycogenolysis resulting in stress hyperglycemia providing the immune system and brain with a ready source of fuel. ACTH, adrenocorticotrophic hormone; $C R H$, corticotrophin releasing hormone; LC/NE, locus ceruleus norepinephrine system; PVN, paraventricular nucleus.

of epinephrine increase 50-fold and norepinephrine levels increase 10-fold [13]. The adrenal medulla is the major source of these released catecholamines [13]. Adrenalectomy eliminates the epinephrine response and blunts the norepinephrine response to hemorrhagic shock [13]. The increased release of stress hormones results in multiple effects (metabolic, cardiovascular and immune) aimed at restoring homeostasis during stress. The HPA axis, sympathoadrenal system and proinflammatory cytokines (TNF- $\alpha$, IL-1 and IL-6) act collectively and synergistically to induce stress hyperglycemia.

The neuroendocrine response to stress is characterized by excessive gluconeogenesis, glycogenolysis and insulin resistance (Figure 1) [5]. Stress hyperglycemia, however, appears to be caused predominantly by increased hepatic output of glucose rather than impaired tissue glucose extraction. The metabolic effects of cortisol include an increase in blood glucose concentration through the activation of key enzymes involved in hepatic gluconeogenesis and inhibition of glucose uptake in peripheral tissues such as the skeletal muscles [5]. Both epinephrine and norepinephrine stimulate hepatic gluconeogenesis and glycogenolysis; norepinephrine has the added effect of increasing the supply of glycerol to the liver via lipolysis. Inflammatory mediators, specifically the cytokines TNF- $\alpha$, IL-1, IL- 6 , and C-reactive protein, also induce peripheral insulin resistance (Figure 2) [5]. In addition, the altered release of adipokines (increased zinc-alpha2 glycoprotein and decreased adiponectin) from adipose tissue during acute illness is thought to play a key role in the development of insulin resistance [14]. The degree of activation of the stress response and the severity of hyperglycemia are related to the intensity of the stressor and the species involved. Hart and colleagues [15] demonstrated that hemorrhage, hypoxia and sepsis were amongst those stressors that resulted in the highest epinephrine and norepinephrine levels. In reviewing the literature, we have demonstrated large interspecies differences in the degree of activation of the HPA axis with stress, with humans having the greatest increase in serum cortisol level (Figure 3) [16].

\section{Mild to moderate stress hyperglycemia is protective during stress and critical illness}

Stress hyperglycemia and insulin resistance are evolutionarily preserved responses that allow the host to survive during periods of severe stress [17]. Insects, worms and all verterbrates, including fish, develop stress 


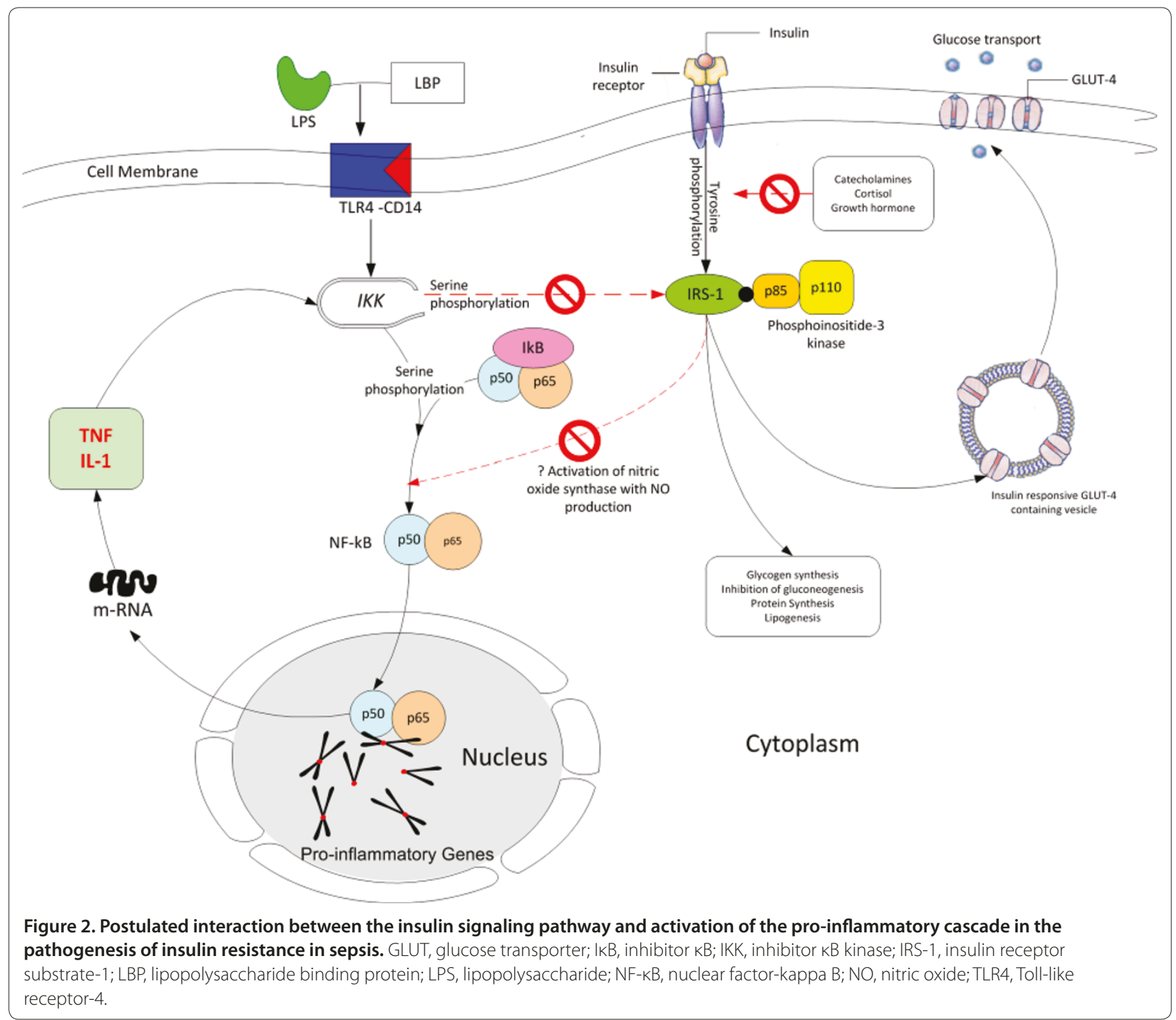

hyperglycemia when exposed to stress $[17,18]$. In animal models of hemorrhagic shock the administration of a hypertonic glucose solution increased cardiac output, blood pressure and improved survival [19]. In these experiments, similar osmolar doses of saline or mannitol, with greater accompanying fluid volumes, failed to produce the sustained blood pressure changes or to improve the survival.

Glucose is largely utilized by tissues that are noninsulin dependent, and these include the central and peripheral nervous system, bone marrow, white and red blood cells and the reticuloendothelial system [20]. It has been estimated that, at rest, non-insulin mediated glucose uptake accounts for 75 to $85 \%$ of the total rate of whole glucose disposal. Glucose is the primary source of metabolic energy for the brain. Cellular glucose uptake is mediated by plasma membrane glucose transporters
(GLUTs), which facilitate the movement of glucose down a concentration gradient across the non-polar lipid cell membrane [20]. These transporters are members of a family of structurally related facilitative glucose transporters that have distinct but overlapping tissue distribution. Although 14 GLUT isoforms have been identified in the human genome, glucose uptake per se is facilitated by GLUT-1, GLUT-3 and GLUT-4 in various tissues. Insulin increases GLUT-4-mediated glucose transport by increasing translocation of GLUT-4 from intracellular stores to the cell membrane [20]. Thermal injury and sepsis have been demonstrated to increase expression of GLUT-1 mRNA and protein levels in the brain and macrophages [21,22]. Concomitantly, stress and the inflammatory response result in decreased translocation of GLUT-4 to the cell membrane. It is likely that proinflammatory mediators, particularly TNF- $\alpha$ and IL-1, 


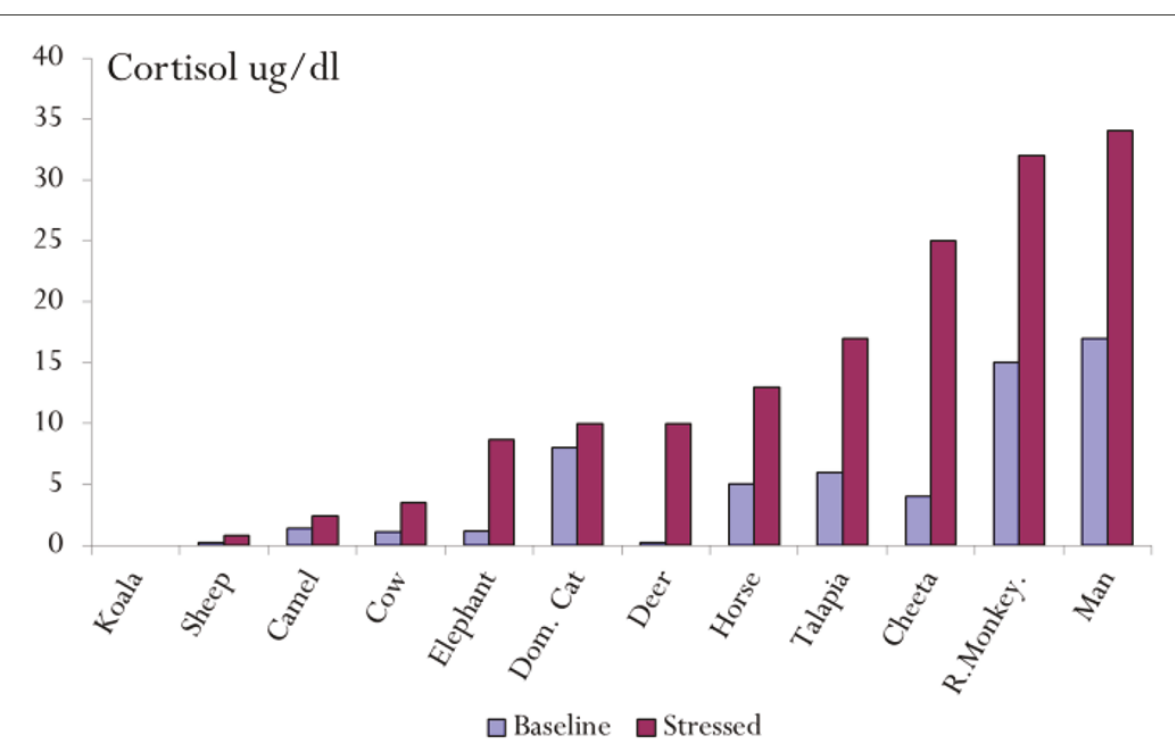

Figure 3. Variability of the basal and stress cortisol level amongst various animal species [16]. Dom. cat, domestic cat; R monkey, rhesus.

are responsible for the reciprocal effects on the surface expression of these glucose transporters (Figure 2) [5]. Elevated TNF- $\alpha$ directly interferes with insulin signal transduction through the phosphorylation of various molecules along the insulin-signaling pathway. During infection, the upregulation of GLUT-1 and downregulation of GLUT-4 may play a role in redistributing glucose away from peripheral tissues towards immune cells and the nervous system.

For glucose to reach a cell with reduced blood flow (ischemia, sepsis), it must diffuse down a concentration gradient from the bloodstream, across the interstitial space and into the cell. Glucose movement is dependent entirely on this concentration gradient, and for adequate delivery to occur across an increased distance, the concentration at the origin (blood) must be greater. Stress hyperglycemia results in a new glucose balance, allowing a higher blood 'glucose diffusion gradient' that maximizes cellular glucose uptake in the face of maldistributed microvascular flow [23]. These data suggest that moderate hyperglycemia (blood glucose of 140 to $220 \mathrm{mg} / \mathrm{dL}$ ) maximizes cellular glucose uptake while avoiding hyperosmolarity. Furthermore, acute hyperglycemia may protect against cell death following ischemia by promoting anti-apoptotic pathways and favoring angiogenesis. In a murine myocardial infarction model, Malfitano and colleagues [24] demonstrated that hyperglycemia increased cell survival factors (hypoxia inducible factor- $1 \alpha$, vascular endothelial growth factor), decreased apoptosis, reduced infarct size and improved systolic function. In this study, hyperglycemia resulted in increased capillary density and a reduction in fibrosis. In vitro and in vivo studies have demonstrated that cardiomyocytes exposed to an insulin-free medium supplemented with high glucose concentrations are resistant to pathological insults such as ischemia, hypoxia and calcium overload [25].

Macrophages play a central role in the host response to injury, infection and sepsis. Macrophage activities include antigen presentation, chemotaxis, phagocytosis, bactericidal activity, cytokine secretion and wound repair. Glucose is the primary metabolic substrate for the macrophage and efficient glucose influx is essential for optimal macrophage function. Macrophages and neutrophils require $\mathrm{NADPH}$ for the formation of the reactive oxygen species, nitric oxide and superoxide as well as many biosynthetic pathways. Metabolism of glucose via the pentose pathway provides the metabolic intermediates required for the generation of NADPH. Following thermal injures, trauma and sepsis, non-insulin mediated glucose uptake is increased. The majority of the increased glucose uptake occurs in macrophage rich tissues [26,27]. These data suggest that the increased energy requirements of activated macrophages and neutrophils during infection and tissue injury are regulated by enhanced cellular glucose uptake related to the increased glucose diffusion gradient and increased expression of glucose transporters. In addition, these mechanisms ensure adequate glucose uptake by neuronal tissue in the face of decreased microvascular flow. Iatrogenic normalization of blood glucose may therefore impair immune and cerebral function at a time of crises. Indeed, two independent groups of investigators using microdialysis and brain pyruvate/lactate ratios demonstrated that attempts at blood glucose normalization in critically ill patients with brain injury were associated with a greater risk of critical reductions in brain glucose levels and brain 
energy crisis [28,29]. Similarly, Duning and colleagues [30] demonstrated that hypoglycemia worsened critical illnessinduced neurocognitive dysfunction. Multiple studies have demonstrated that even moderate hypoglycemia is harmful and increases the mortality of critically ill patients [31,32]. In summary, these data suggest that stress hyperglycemia provides a source of fuel for the immune system and brain at a time of stress and that attempts to interfere with this evolutionarily conserved adaptive response is likely to be harmful.

\section{The deleterious effects of chronic hyperglycemia and the benefit of acute hyperglycemia: balancing the good with the bad}

Chronic hyperglycemia in patients with diabetes is associated with a myriad of harmful complications. The adverse outcomes associated with chronic hyperglycemia are attributed to the pro-inflammatory, pro-thrombotic and pro-oxidant effects observed with increased glucose levels. Brownlee [33] has suggested a unifying mechanism to explain the pathobiology of the long-term complications of diabetes - the overproduction of superoxide by the mitochondrial electron chain. The duration and degree of hyperglycemia appears to be critical in determining whether hyperglycemia is protective or harmful. This contention is supported by a number of experimental models. Acute hyperglycemia limits myocardial injury following hypoxia [34]; however, chronic treatment of cardiomyocytes with a high glucose content medium increased the rate of cell death [35]. This issue was specifically addressed by $\mathrm{Xu}$ and colleagues [36], who measured infarct size following a left coronary artery ischemia/reperfusion injury following short- (4 weeks) and long-term (20 weeks) hyperglycemia. In this study, the number of dead myocytes decreased with short-term hyperglycemia while the number of dead myocytes increased markedly in the 20 week hyperglycemia group compared with the time-matched control group. Furthermore, extracellular signal-regulated kinase 1/2 (ERK 1/2), which plays an important role in cell proliferation and protein synthesis, increased with short-term hyperglycemia but was reduced with long-term hyperglycemia. In a similar study, Ma and colleagues [25] demonstrated that 2 weeks of streptozotocin-induced diabetes reduced pro-apoptotic signals and myocardial infarct size compared with normoglycemic controls or rats that had been diabetic for 6 weeks. In this study, phosphorylation of AKT, a prosurvival signal, was significantly increased after 2 weeks of diabetes. However, after 6 weeks of diabetes, lipid peroxidation was increased and levels of vascular endothelial growth factor and plasma nitric oxide were reduced compared with controls or rats diabetic for 2 weeks. These studies differ from those of Van den Berghe and colleagues [37,38], who in experimental models have demonstrated that acute hyperglycemia induces mitochondrial and organ dysfunction. However, it must be recognized that similar to their 'landmark' study in critically ill patients [39], these animals received parenteral nutrition. Parenteral nutrition results in cellular glucose overload and is an independent predictor of increased morbidity and mortality [40-42].

These data suggest that acute hyperglycemia may be protective and may result in greater plasticity and cellular resistance to ischemic and hypoxic insults. It is possible, although not proven, that severe stress hyperglycemia (blood glucose $>220 \mathrm{mg} / \mathrm{dL}$ ) may be harmful. Due to its effects on serum osmolarity, severe stress hyperglycemia may result in fluid shifts. In addition, severe hyperglycemia exceeds the renal threshold, resulting in an osmotic diuresis and volume depletion. It is, however, unclear at what threshold stress hyperglycemia may become disadvantageous. It is likely that severe stress hyperglycemia may occur more frequently in patients with underlying impaired glucose tolerance [43].

\section{The Leuven trial and glycemic control in the ICU}

In 2001, Van den Berghe and coworkers [39] published the 'Leuven Intensive Insulin Therapy Trial' in which they demonstrated that tight glycemic control (targeting a blood glucose of 70 to $110 \mathrm{mg} / \mathrm{dL}$ ) using intensive insulin therapy improved the outcome of critically ill surgical patients. The results of this single-center, investigatorinitiated and unblinded study have yet to be reproduced. This study has a number of serious limitations with concern regarding the biological plausibility of the findings $[8,44]$. Following the above study, tight glycemic control became rapidly adopted as the standard of care in ICUs throughout the world. Tight glycemic control then spread outside the ICU to the step-down unit, regular floor and even operating room. Without any credible evidence that intensive glycemic control improves the outcome of hospitalized patients, this has become a world-wide preoccupation and 'compliance' with glycemic control is used as a marker of the quality of care provided. Indeed, as recently as 2012, the Endocrine Society Clinical Practice Guideline on the management of hyperglycemia in hospitalized patients stated that 'observational and randomized controlled studies indicate that improvement in glycemic control results in lower rates of hospital complications' and they provide strong recommendations for glycemic control [45]. The 2012 Clinical Practice Guidelines published by the American College of Critical Care Medicine suggest that 'a blood glucose $>150 \mathrm{mg} / \mathrm{dl}$ should trigger interventions to maintain blood glucose below that level and absolutely < $180 \mathrm{mg} / \mathrm{dl}$ ' [46]. We believe the evidence demonstrates that these assertions and recommendations are without a scientific basis and may be potentially detrimental to patients. 


\section{Conclusion}

Although an association between the degree of hyperglycemia and poor clinical outcomes exist in the hospitalized patient, there are few data demonstrating causation. Randomized, controlled studies do not support intensive insulin therapy. Furthermore, improving care through the acute treatment of mild or moderate hyperglycemia in the acutely ill hospitalized patient lacks biologic plausibility. We advocate more studies comparing standard care (glycemic target between 145 and $180 \mathrm{mg} / \mathrm{dL}$ ) as delivered in the NICE-SUGAR trial with a more tolerant management of stress hyperglycemia (target between 180 and $220 \mathrm{mg} / \mathrm{dL}$ ).

\section{Abbreviations}

GLUT, glucose transporter; HPA, hypothalamic-pituitary-adrenal; IL, interleukin; TNF, tumor necrosis factor.

\section{Competing interests}

The authors of this paper have no financial interest in any of the products mentioned in this paper

\section{Author details}

'Division of Pulmonary and Critical Care Medicine, Eastern Virginia Medical School, Norfolk, VA, USA. ${ }^{2}$ Australian and New Zealand Intensive Care Research Centre, Melbourne, Australia.

Published: 6 March 2013

\section{References}

1. Bernard C: Lecons sur les Phenomenes de la Vie Communs aux Animaux et aux Vegetaux. Paris, France: JB Bailliere et fils; 1878.

2. Badawi O, Waite MD, Fuhrman SA, Zuckerman $I H$ : Association between intensive care unit-acquired dysglycemia and in-hospital mortality. Crit Care Med 2012, 40:3180-3188.

3. Bruno A, Levine SR, Frankel MR, Brott TG, Lin Y, Tilley BC, Lyden PD, Broderick JP, Kwiatkowski TG, Fineberg SE: Admission glucose level and clinical outcomes in the NINDS rt-PA Stroke Trial. Neurology 2002, 59:669-674.

4. Capes SE, Hunt D, Malmberg K, Gerstein HC: Stress hyperglycaemia and increased risk of death after myocardial infarction in patients with and without diabetes: a systematic overview. Lancet 2000, 355:773-778.

5. Dungan K, Braithwaite SS, Preiser JC: Stress hyperglycemia. Lancet 2009, 373:1798-1807.

6. Wiener RS, Wiener DC, Larson RJ: Benefits and risks of tight glucose control in critically ill adults: a meta-analysis. JAMA 2008, 300:933-944.

7. Kansagara D, Fu R, Freeman M, Wolf F, Helfand M: Intensive insulin therapy in hospitalized patients: A systematic review. Ann Intern Med 2011, 154:268-282.

8. Marik PE, Preiser JC: Towards understanding tight glycemic control in the ICU: A systemic review and meta-analysis. Chest 2010, 137:544-551.

9. Intensive versus conventional glucose control in critically ill patients: The NICE-Sugar Study Investigators. N Engl J Med 2009, 360:1283-1297.

10. Green JP, Berger T, Garg N, Horeczko T, Suarez A, Radeos MS, Hagar Y, Panacek EA: Hyperlactemia affects the association of hyperglycemia with mortality in nondiabetic adults with sepsis. Acad Emerg Med 2012, 19:1268-1275.

11. Tiruvoipati R, Chiezey B, Lewis D, Ong K, Villanueva E, Haji K, Botha J: Stress hyperglycemia may not be harmful in critically ill patients with sepsis. J Crit Care 2012, 27:153-158.

12. Marik PE: Critical illness related corticoseroid insufficiency. Chest 2009 135:181-193.

13. Chernow B, Rainey TR, Lake CR: Endogenous and exogenous catecholamines in critical care medicine. Crit Care Med 1982, 10:409-416.

14. Jernas M, Olsson B, Sjoholm K, Sjogren A, Rudemo M, Nellgard B, Carlsson LM, Sjostrom CD: Changes in adipose tissue gene expression and plasma levels of adipokines and acute-phase proteins in patients with critical illness. Metabolism 2009, 58:102-108.

15. Hart BB, Stanford GG, Ziegler MG, Lake CR, Chernow B: Catecholamines: study of interspecies variation. Crit Care Med 1989, 17:1203-1218.
16. Marik PE, Levitov A: The "koala stress syndrome" and adrenal responsiveness in the critically ill. Intensive Care Med 2010, 36:1805-1806.

17. Soeters MR, Soeters PB: The evolutionary benefit of insulin resistance. Clin Nutrition 2012, 31:1002-1007.

18. Barreto RE, Volpato GL: Stress responses of the fish Nile tilapia subjected to electroshock and social stressors. Braz J Med Biol Res 2006, 39:1605-1612.

19. McNamara JJ, Mills D, Aaby GV: Effect of hypertonic glucose on hemorrhagic shock in rabbits. Ann Thorac Surg 1970, 9:116-121.

20. Shepherd PR, Kahn BB: Glucose transporters and insulin actionimplications for insulin resistance and diabetes mellitus. N Eng/ J Med 1999 341:248-257.

21. Gamelli RL, Liu H, He LK, Hofmann CA: Alterations of glucose transporter mRNA and protein levels in brain following thermal injury and sepsis in mice. Shock 1994, 1:395-400.

22. Maratou E, Dimitriadis G, Kollias A, Boutati E, Lambadiari V, Mitrou P, Raptis SA Glucose transporter expression on the plasma membrane of resting and activated white blood cells. Eur J Clin Invest 2007, 37:282-290.

23. Losser MR, Damoisel C, Payen D: Bench-to-bedside review: Glucose and stress conditions in the intensive care unit. Crit Care 2010, 14:231.

24. Malfitano C, Alba Loureiro TC, Rodriques B, Sirvente R, Salemi VM, Rabechi NB, Lacchini S, Curi R, Irigoyen MC: Hyperglycaemia protects the heart after myocardial infarction: aspects of programmed cell survival and cell death. Eur J Heart Failure 2010, 12:659-667.

25. Ma G, Al-Shabrawey M, Johnson JA, Datar R, Tawfik HE, Guo D, Caldwell RB, Caldwell RW: Protection against myocardial ischemia/reperfusion injury by short-term diabetes: enhancement of VEGF formation, capillary density, and activation of cell survival signaling. Naunyn-Schmiedebergs Arch Pharmacol 2006, 373:415-427.

26. Lang $\mathrm{CH}$, Dobrescu C: Gram-negative infection increases noninsulinmediated glucose disposal. Endocrinology 1991, 128:645-653.

27. Meszaros K, Lang CH, Bagby GJ, Spitzer JJ: In vivo glucose utilization by individual tissues during nonlethal hypermetabolic sepsis. FASEB J 1988, 2:3083-3086

28. Oddo M, Schmidt M, Carrera E, Badjatia N, Connolly ES, Presciutti M, Ostapkovich ND, Levine JM, Le Roux P, Mayer SA: Impact of tight glycemic control on cerebral glucose metabolism after severe brain injury: A microdialysis study. Crit Care Med 2008, 36:33233-3238.

29. Vespa P, MCArthur DL, Stein N, Huang SC, Shao W, Filippou M, Etchepare M, Glenn T, Hovda DA: Tight glycemic control increases metabolic distress in traumatic brain injury: a randomized controlled within-subjects trial. Crit Care Med 2012, 40:1923-1929.

30. Duning $\mathrm{T}$, van $\mathrm{dH}$, I, Dickmann A, Volkert T, Wempe C, Reinholz J, Lohmann $\mathrm{H}$ Freise $H$, Ellger B: Hypoglycemia aggravates critical illness-induced neurocognitive dysfunction. Diabetes Care 2010, 33:639-644

31. Park S, Kim DG, Suh GY, Kang JG, Ju YS, Lee YJ, Park JY, Lee SW, Jung KS: Mild hypoglycemia is independently associated with increased risk of mortality in patients with sepsis: a three year retrospective observational study. Crit Care 2012, 16:R189.

32. Hypoglycemia and risk of death in critically ill patients. N Engl J Med 2012 367:1108-1118.

33. Brownlee M: The pathobiology of diabetic complications: a unifying mechanism. Diabetes 2005, 54:1615-1625.

34. Frustaci A, Kajstura J, Chimenti C, Jakoniuk I, Leri A, Maseri A, Nadal-Ginard B: Myocardial cell death in human diabetes. Circ Res 2000, 87:1123-1132.

35. Fiordaliso F, Leri A, Cesselli D, Limana F, Safai B, Nadal-Ginard B, Anversa P, Kajstura J: Hyperglycemia activates p53 and p53-regulated genes leading to myocyte cell death. Diabetes 2001, 50:2363-2375.

36. Xu G, Takashi E, Kudo M, Ishiwata T, Naito Z: Contradictory effects of shortand long-term hyperglycemias on ischemic injury of myocardium via intracellular signaling pathway. Exp Mol Pathol 2004, 76:57-65.

37. Vanhorebeek I, Ellger B, De VR, Boussemaere M, Debaveye Y, Perre SV, Rabbani N, Thornalley PJ, van den Berghe G, Vanhorebeek I, Ellger B, De Vos R, Boussemaere M, Debaveye Y, Perre SV, Rabbani N, Thornalley PJ, Van den Berghe G: Tissue-specific glucose toxicity induces mitochondrial damage in a burn injury model of critical illness. Crit Care Med 2009, 37:1355-1364.

38. Gunst J, Derese I, Aertgeerts A, Ververs EJ, Wauters A, van den Berghe G, Vanhorebeek I: Insufficient autophagy contributes to mitochondrial dysfunction, organ failure, and adverse outcome in an animal model of critical illness. Crit Care Med 2013, 41:177-189.

39. Van den Berghe G, Wouters P, Weekers F, Verwaest C, Bruyninckx F, Schetz M, Vlasselaers D, Ferdinande P, Lauwers P, Bouillon R: Intensive insulin therapy 
in critically ill patients. N Eng/ J Med 2001, 345:1359-1367.

40. Heyland DK, MacDonald S, Keefe L, Drover JW: Total parenteral nutrition in the critically ill patient: a meta-analysis. JAMA 1998, 280:2013-2019.

41. van der Voort PH, Feenstra RA, Bakker AJ, Heide L, Boerma EC, der H, I: Intravenous glucose intake independently related to intensive care unit and hospital mortality: an argument for glucose toxicity in critically ill patients. Clin Endocrinol 2006, 64:141-145.

42. Casaer MP, Mesotten D, Hermans G, Wouters PJ, Schetz M, Meyfroidt G, van Cromphaut $S$, Ingels $C$ : Early versus late parenteral nutrition in critically ill adults. N Engl J Med 2011, 365:506-517.

43. Macintyre EJ, Majumdar SR, Gamble JM, Minhas-Sandhu JK, Marrie TJ, Eurich DT: Stress hyperglycemia and newly diagnosed diabetes in 2124 patients hospitalized with pneumonia. Am J Med 2012, 125:1036-1023.

44. Bellomo R, Egi M: What is a NICE-SUGAR for patients in the intensive care unit? Mayo Clin Proc 2009, 84:400-402.
45. Umpierrez GE, Hellman R, Korytkowski MT, Kosiborod M, Maynard GA, Montori VM, Seley JJ, van den Berghe G: Management of hyperglycemia in hospitalized patients in non-critical care setting: an endocrine society clinical practice guideline. J Clin Endocrinol Metab 2012, 97:16-38.

46. Jacobi J, Bircher N, Krinsley J, Agus M, Braithwaite SS, Deutschman C, Freire AX, Greehan D, Kohl B, Nasraway SA, Rigby M, Sands K, Schallom L, Taylor B, Umpierrez G, Mazuski J, Schunemann H: Guidelines for the use of an insulin infusion for the management of hyperglycemia in critically ill patients. Crit Care Med 2012, 40:3251-3276.

doi:10.1186/cc12514

Cite this article as: Marik PE, Bellomo R: Stress hyperglycemia: an essential survival response! Critical Care 2013, 17:305 